\title{
Flame synthesis of titania particles from titanium tetraisopropoxide in premixed flames
}

\author{
C.L. Yeh ${ }^{\mathrm{a}, *}$, S.H. Yeh ${ }^{\mathrm{b}}$, H.K. Ma ${ }^{\mathrm{b}}$ \\ ${ }^{a}$ Department of Mechanical and Automation Engineering, Da-Yeh University, 112 Shan-Jiau Rd., Da-Tsuen, Changhua 51505, Taiwan \\ ${ }^{\mathrm{b}}$ Department of Mechanical Engineering, National Taiwan University, Taipei, Taiwan
}

Received 16 June 2003; received in revised form 20 March 2004; accepted 22 April 2004

\begin{abstract}
An experimental investigation of flame synthesis of titania particles was conducted in premixed flames. The titanium precursor and silicon dopant used in this study were titanium tetraisopropoxide (TTIP) and hexamethyldisiloxane (HMDS), respectively. The objective of this study was to investigate the influence of flame condition, TTIP concentration, and HMDS on the phase composition and particle morphology of titania synthesized in flames. It was found that the anatase content of titania particles made in flames was appreciably increased by the increase of oxygen concentration in the oxidizer. The increase of flame temperature results in the decrease of anatase content. A significant increase in rutile content of titania particles was observed by increasing the particle residence time at high temperatures. The doping of HMDS in flames inhibits the transformation of anatase to rutile phase and, therefore, reduces the rutile content of product particles. Under the flame doped with low concentrations of HMDS, titania particles with $\mathrm{SiO}_{2}$ particle agglomerates attached were produced. Further increase of the HMDS concentration up to the $\mathrm{Si}$ to $\mathrm{Ti}$ molar ratio equal to 0.375 results in the formation of a large amount of $\mathrm{SiO}_{2}$ agglomerates in the product. (C) 2004 Elsevier B.V. All rights reserved.
\end{abstract}

Keywords: Flame synthesis; Titania particle; Anatase phase; Rutile phase; TTIP; HMDS

\section{Introduction}

Titania $\left(\mathrm{TiO}_{2}\right)$ powders have been produced by the socalled 'chloride process' where oxidation of titanium tetrachloride $\left(\mathrm{TiCl}_{4}\right)$ vapor takes place in a flame aerosol reactor [1]. Titania particles crystallize mostly in two polymorphic forms: rutile and anatase. Anatase is a metastable phase, which transforms into rutile at high temperatures [2]. Depending on their crystalline phases, titania particles of anatase phase have been proved to be more active photocatalysts in environmental remediation than rutile phase [3], while rutile titania particles have been used as white pigments [1]. Due to their unique photocatalytic properties, anatase titania powders have attracted great interest in decontamination treatment of wastewater or gas phase degradation of industrial organic pollutants [2].

\footnotetext{
* Corresponding author. Tel.: +886-4-8511888x2118; fax: +886-48511215.

E-mail address: clyeh@mail.dyu.edu.tw (C.L. Yeh).
}

The formation of titania particles by the flame synthesis using $\mathrm{TiCl}_{4}$ as the precursor has been extensively studied [4]. Fotou et al. [5] produced ultrafine titania powders with a high specific surface area $\left(>100 \mathrm{~m}^{2} / \mathrm{g}\right)$ and almost complete anatase phase by oxidation of $\mathrm{TiCl}_{4}$ in a $\mathrm{CH}_{4} /$ Air coflow diffusion flame. Pratsinis et al. [6] found that the specific surface area of $\mathrm{TiO}_{2}$ powders increased from 15 to $120 \mathrm{~m}^{2} / \mathrm{g}$ and the rutile fraction decreased from 15 to $0.1 \mathrm{wt} . \%$ by switching the $\mathrm{TiCl}_{4}$ in the fuel stream to the oxidant stream of a coflow diffusion flame burner. This implies that the better the mixing between oxidant and $\mathrm{TiCl}_{4}$, the finer are the product titania particles and the higher is the anatase content. Experimental results by Rulison et al. [7] also indicated that mainly anatase $\mathrm{TiO}_{2}$ powders were obtained by feeding $\mathrm{TiCl}_{4}$ precursor only into the oxidizer stream of a counterflow diffusion flame burner. On the contrary, largely rutile $\mathrm{TiO}_{2}$ powders were yielded by feeding $\mathrm{TiCl}_{4}$ only into the fuel stream. This observation was explained by the relatively low concentration of gaseous oxygen during the particle formation, resulting in a high concentration of the oxygen vacancies that enhance the transformation of anatase to rutile phase [7]. 
Vemury and Pratsinis [8] showed that the introduction of dopant $\mathrm{SiCl}_{4}$ into a diffusion flame, where the oxidation of $\mathrm{TiCl}_{4}$ occurred, inhibited the transformation of anatase to rutile $\mathrm{TiO}_{2}$ powders. In contrast, the addition of $\mathrm{SnCl}_{4}$ or $\mathrm{AlCl}_{3}$ as the dopant enhanced the transformation of anatase to rutile phase. Similar results were also observed by Akhtar et al. $[9,10]$ from experiments in an electrically heated tubular flow reactor. Effects of the dopant on phase composition and particle morphology of titania were determined by the ionic radius and valence of the dopant species $[9,10]$. Fotou et al. [5] indicated that the photocatalytic activity of Si-doped titania powders was improved, due to an increase in the anatase content and specific surface area. Hung and Katz [11] employed $\mathrm{TiCl}_{4}$ and $\mathrm{SiCl}_{4}$ to synthesize $\mathrm{TiO}_{2}-$ $\mathrm{SiO}_{2}$ mixed powders in an $\mathrm{H}_{2} / \mathrm{O}_{2}$ counterflow diffusion flame, and produced $\mathrm{SiO}_{2}$-encapsulated $\mathrm{TiO}_{2}$ particles at $\mathrm{SiCl}_{4}$ to $\mathrm{TiCl}_{4}$ concentration ratios in the range of $1.0-3.0$. At a low $\mathrm{SiCl}_{4}$ to $\mathrm{TiCl}_{4}$ molar ratio of $0.15, \mathrm{TiO}_{2}$ particles covered with discrete $\mathrm{SiO}_{2}$ particles were obtained. In their study [11], the synthesized $\mathrm{TiO}_{2}$ is rutile and $\mathrm{SiO}_{2}$ is amorphous. By using $\mathrm{Al}\left(\mathrm{CH}_{3}\right)_{3}$ and $\mathrm{TiCl}_{4}$ as the precursors in a counterflow diffusion flame, Hung et al. [12] produced $\mathrm{Al}_{2} \mathrm{O}_{3}-\mathrm{TiO}_{2}$ mixed powders consisting of rutile $\mathrm{TiO}_{2}, \gamma$ $\mathrm{Al}_{2} \mathrm{O}_{3}$, and aluminum titanate $\left(\mathrm{Al}_{2} \mathrm{TiO}_{5}\right)$.

With the application of an electrical field across a diffusion flame by needle electrodes, Vemury and Pratsinis [13] reduced the particle residence time at high temperatures, resulting in a decrease in the $\mathrm{TiO}_{2}$ particle size and rutile content. The effect of electrical charges on the characteristics of flame-synthesized nanopowders was further investigated by Vemury et al. [14], showing that electric fields reduced the primary particle size of $\mathrm{TiO}_{2}$, the agglomerate size of $\mathrm{SnO}_{2}$, and both the agglomerate and primary size of $\mathrm{SiO}_{2}$. Lee and Choi [15] recently applied $\mathrm{CO}_{2}$ laser beam irradiation on aggregates formed in diffusion flames to control the size, morphology, and crystalline phase of $\mathrm{TiO}_{2}$ nanoparticles from the oxidation of $\mathrm{TiCl}_{4}$. It was found that the rutile particles were transformed into the anatase form under the laser irradiation, which caused the melting of $\mathrm{TiO}_{2}$ particles and the subsequent recrystallization to metastable anatase phase.

Besides titanium tetrachloride $\left(\mathrm{TiCl}_{4}\right)$, titanium tetraisopropoxide (TTIP) has been recognized as the precursor for the $\mathrm{TiO}_{2}$ powder synthesis [16]. In a premixed flame of $\mathrm{CH}_{4}$ and oxygen, Arabi-Katbi et al. [17] pointed out that the rutile titania content decreased with the increasing TTIP concentration, which led to an increase in flame temperature. This observation is in contradiction with the understanding that the transformation from anatase to rutile phase is enhanced by higher temperatures. Arabi-Katbi et al. [17] contributed this disagreement to the insufficient particle residence time and the presence of carbon in their flame conditions. Kammler et al. [18] found the rutile content of product powders to be slightly increased by applying an electric field across a premixed flame added with TTIP, due to the rapid quenching which favors the anatase to rutile phase transfor- mation. A novel diffusion flame reactor by oxidation of TTIP was developed by Wegner et al. [19], in which particle-laden flames were quenched rapidly by expansion through a critical flow nozzle, resulting in titania particles down to $5 \mathrm{~nm}$ in diameter with little degree of agglomerate.

Based upon the literature mentioned above, most of the previous studies employed the $\mathrm{TiCl}_{4}$ as the precursor in diffusion flames for the titania synthesis and established a comprehensive understanding. However, the details of titania synthesis associated with the other precursor TTIP oxidized in flames are not yet well characterized. Therefore, this study aimed at conducting an experimental investigation of flame synthesis of titania particles by the TTIP oxidation in premixed $\mathrm{CH}_{4} / \mathrm{O}_{2} / \mathrm{N}_{2}$ flames. Effects of precursor concentration, flame temperature, oxygen mole fraction, and particle residence time on the phase composition and morphology of titania particles were studied. The synthesized $\mathrm{TiO}_{2}$ particles were characterized by an X-ray diffractometer (XRD) and a transmission electron microscope (TEM) for the analysis of phase composition and particle morphology, respectively. In addition, the role of an organosilicon compound, hexamethyldisiloxane (HMDS), as the dopant was investigated, because silicon ( $\mathrm{Si}$ ) was effective in suppressing the anatase to rutile conversion. This study represents the first attempt using organosilicon species instead of $\mathrm{SiCl}_{4}$ as a dopant in the flame synthesis of titania. Changes in the particle morphology, chemical composition, and crystalline phase of product powders with the dopant concentration were also examined.

\section{Methods of approach}

\subsection{Experimental setup}

The premixed burner used in this study is shown in Fig. 1 and the detailed description of this burner was previously given [20]. In brief, the bottom portion of this burner is in a divergent shape to decrease the flow velocity, and is filled with small steel balls to promote the mixing of fuel and oxidizer. The upper portion is a stainless steel tube with a diameter of $12 \mathrm{~mm}$. Near the exit port of the burner, several layers of the steel wire screen were installed to ensure the uniformity of gas flow.

In this study, titania $\left(\mathrm{TiO}_{2}\right)$ particles were synthesized in premixed flames by using titanium tetraisopropoxide $\mathrm{Ti}\left(\mathrm{OC}_{3} \mathrm{H}_{7}\right)_{4}$ (TTIP, 97\% purity, Acros Organics) as the titanium precursor. In the experiment, dry air was bubbled through a washing bottle containing liquid TTIP to deliver the TTIP vapor to the burner, as shown in Fig. 1. Premixed combustible gases were prepared by methane $\left(\mathrm{CH}_{4}\right)$, oxygen, and nitrogen, which were mixed in a mixing chamber filled with small glass balls. Before entering the burner, the combustible mixture was further mixed with TTIP vapor carried by a dry air stream. In order to prevent any condensation of the precursor, all gas lines downstream 


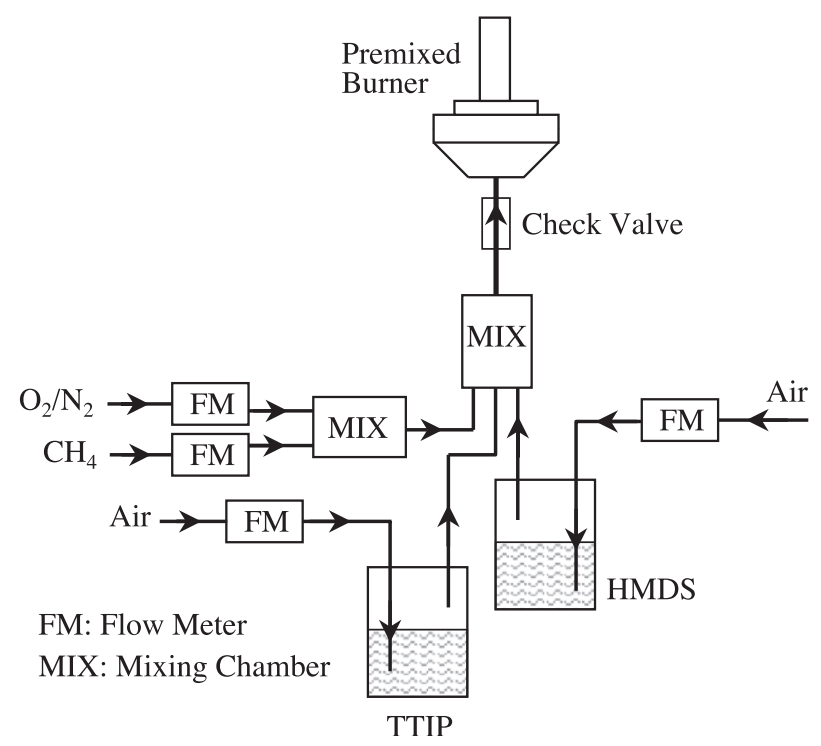

Fig. 1. Schematic diagram of experimental setup to study flame synthesis of $\mathrm{TiO}_{2}$ particles in premixed flames.

the TTIP bubbler and the burner were wrapped with heating tapes to maintain them at $125{ }^{\circ} \mathrm{C}$. The synthesized $\mathrm{TiO}_{2}$ particles in the postflame region were collected by the deposition on a stainless steel plate, which was inserted into the flame zone at different heights $(h)$ above the burner exit port. Flame temperatures were measured by $125 \mu \mathrm{m} \mathrm{Pt} /$ $\mathrm{Pt}-13 \% \mathrm{Rh}$ thermocouples and were corrected for the radiative heat loss [20]. Furthermore, because the time required for a thermocouple traveling in the flame zone to detect a temperature profile was relatively short, the deposition of synthesized particles on the thermocouple bead was almost negligible in this study.

As mentioned above, the addition of dopants is an effective way of controlling the phase composition, aggregate size, and morphology of titania particles. The siliconcontaining dopant used in this study was an organosilicon compound hexamethyldisiloxane $\mathrm{Si}_{2} \mathrm{O}\left(\mathrm{CH}_{3}\right)_{6}$ (HMDS, 98\% purity, Acros Organics). The reason of selecting HMDS rather than the commonly used dopant $\mathrm{SiCl}_{4}$ is that both TTIP and HMDS are metalorganic compounds. Thus, the powder synthesis flame in this study is a chlorine-free flame without any corrosive hazard. Similarly, HMDS vapor was carried by bubbling dry air through the HMSD liquid, as shown in Fig. 1.

\subsection{Test conditions}

Premixed $\mathrm{CH}_{4} / \mathrm{O}_{2} / \mathrm{N}_{2}$ flames were prepared with three equivalence ratios $(\phi)$ equal to $0.7,0.8$, and 1.0 . The equivalence ratio was used to describe the premixed $\mathrm{CH}_{4} /$ $\mathrm{O}_{2} / \mathrm{N}_{2}$ flame, and was defined as the ratio of actual fueloxidizer ratio to the ratio for a stoichiometric process. Therefore, it was calculated based upon the quantities of the fuel $\left(\mathrm{CH}_{4}\right)$ and the oxidizer $\left(\mathrm{O}_{2}\right.$ and $\left.\mathrm{N}_{2}\right)$ in the reactant mixture. Since the amounts of precursor TTIP and dopant
HMDS introduced into the premixed mixture were very small, they were not considered in the calculation of the equivalence ratio.

Nitrogen gas was used as a diluent in the oxidizer stream. In order to investigate the influence of oxygen concentration on the titania synthesis, the oxidizer was prepared to have the composition including four molar ratios of oxygen to nitrogen $\left(\mathrm{O}_{2} / \mathrm{N}_{2}\right)$, which were $20 / 80,30 / 70,40 / 60$, and 50 / 50. The amount of TTIP vapor introduced into the flame zone was calibrated with respect to the carrying-gas flow rate. The concentration of TTIP in the premixed combustible mixture was adjusted to have molar fractions of $0.22 \%$, $0.4 \%$, and $0.6 \%$. The effect of dopant on the product powders was studied by adding HMDS vapor into the combustible mixture and controlling the atomic ratio of $\mathrm{Si}$ to $\mathrm{Ti}(\mathrm{Si} / \mathrm{Ti})$ in the range from 0.2 to 0.45 . When the atomic ratio of $\mathrm{Si}$ to $\mathrm{Ti}$ was varied, the quantities of fuel and oxidizer had to be properly adjusted in order to hold the equivalence ratio constant. In addition, under the condition doping with HMDS the mole fraction of TTIP in the reactant mixture was set at a constant value of $0.4 \%$.

\subsection{Product powder analysis}

The size and morphology of synthesized particles were examined under a transmission electron microscope (TEM, Hitachi H-7110) operating at $75 \mathrm{kV}$. Phase composition of titania particles were determined by the X-ray diffraction (XRD) analysis (Philips X'Pert Pro; with $\mathrm{CuK}_{\alpha}$ radiation). The weight fraction of anatase and rutile phases in the sample was calculated from the relative intensity of the strongest peaks corresponding to anatase $\left[2 \theta=25.3^{\circ}\right.$ for the (101) reflection of anatase] and rutile $\left[2 \theta=27.5^{\circ}\right.$ for the (110) reflection of rutile] peaks, as described by Spurr and Myers [21]. The weight fraction of anatase phase $\left(Y_{\mathrm{A}}\right)$ in the $\mathrm{TiO}_{2}$ sample is determined by [21].

$Y_{\mathrm{A}}=\frac{1}{1+1.26\left(I_{\mathrm{R}} / I_{\mathrm{A}}\right)}$

where $I_{\mathrm{A}}$ and $I_{\mathrm{R}}$ are the intensities of the strongest XRD peaks for anatase and rutile titania, respectively.

\section{Results and discussion}

\subsection{Flame temperature measurement}

Fig. 2 shows the measured axial temperature profiles of premixed flames (without any addition of TTIP) under different equivalence ratios $(\phi)$. Profiles show that the temperature increases with the axial distance from the burner exit and reaches a nearly constant temperature region, followed by a gradual decline. These profiles correspond to the typical temperature variation of premixed flames along the burner axis. Since the flame with an equivalence 


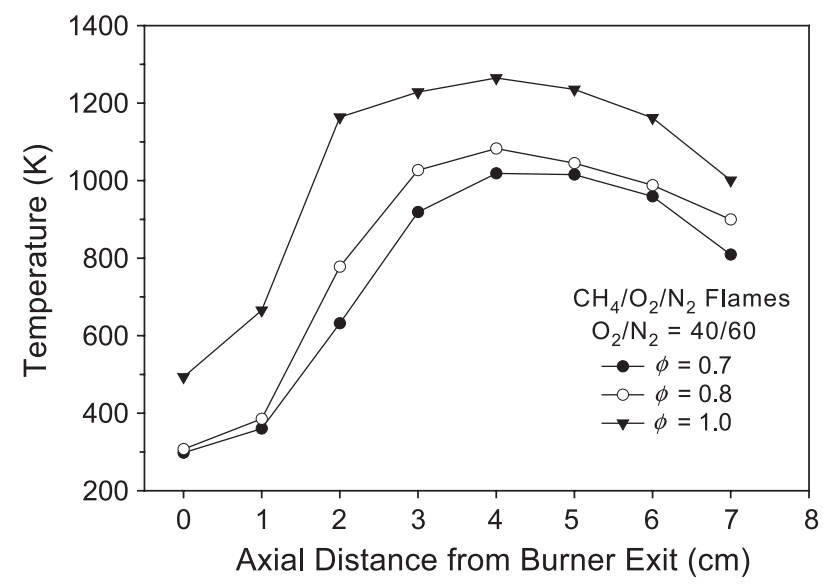

Fig. 2. Measured axial temperatures of premixed flames under different equivalence ratios.

ratio equal to 1.0 represents a stoichiometric condition, the flame temperature at $\phi=1$ is higher than those at $\phi=0.8$ and 0.7 , which are fuel-lean situations. Moreover, the flame temperature at $\phi=0.8$ is slightly higher than at $\phi=0.7$. The effect of oxidizer composition on the flame temperature is shown in Fig. 3. It was found that the flame temperature increases with the increase of $\mathrm{O}_{2}$ concentration in the oxidizer, due to the reduction of nitrogen that acts as a diluent in the flame. As also can be seen from Fig. 3, the flame with a higher $\mathrm{O}_{2}$ to $\mathrm{N}_{2}$ ratio in the oxidant exhibits a faster temperature rise and a more uniform temperature in the postflame region. It is useful to note that the gas temperature at the burner exit is mainly influenced by the temperature of burned gas, due to the heat feedback from the postflame region. Since no preheating of the reactant mixture was conducted under the condition without TTIP, as shown in Figs. 2 and 3, the variation of gas temperature between 300 and $500 \mathrm{~K}$ at the burner exit was observed.

The addition of TTIP leads to an increase in flame temperature, as shown in Fig. 4. The temperature profile of TTIP-added flame remains similar to that of TTIP-free

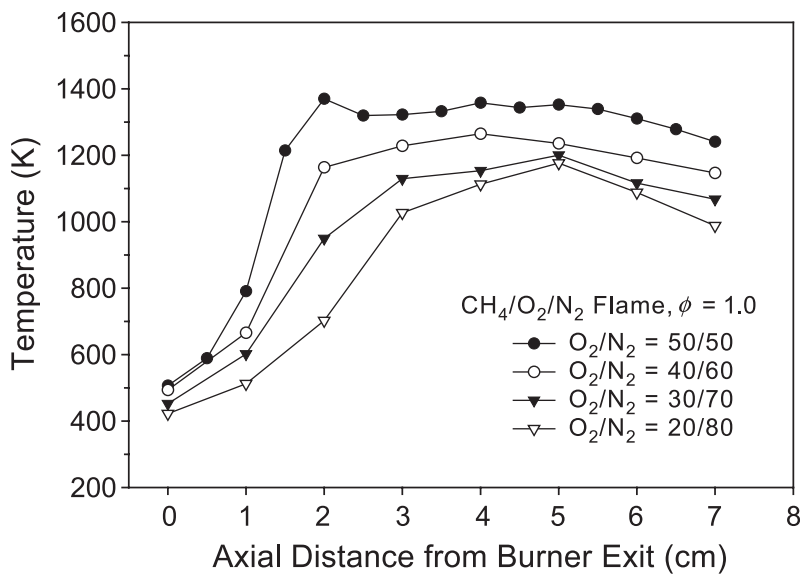

Fig. 3. Measured axial temperatures of premixed flames with different $\mathrm{O}_{2}$ to $\mathrm{N}_{2}$ molar ratios in oxidizer.

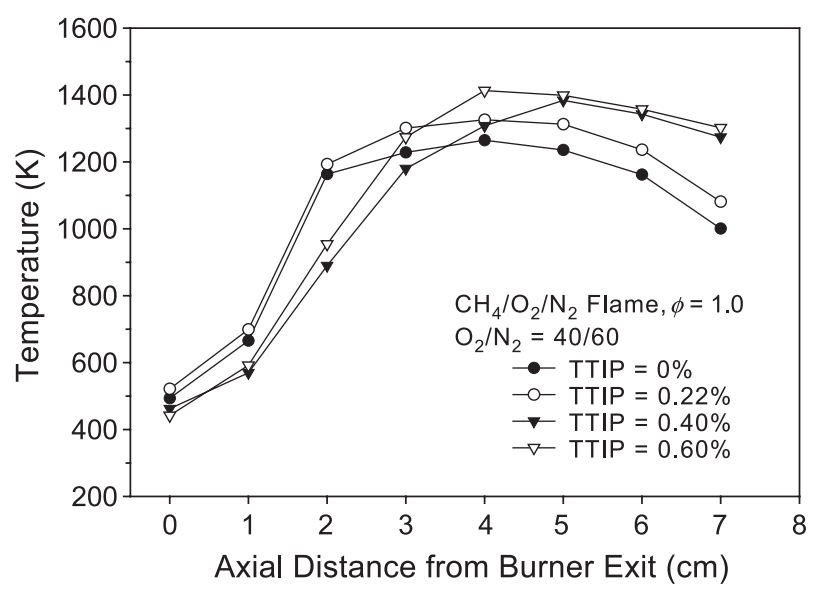

Fig. 4. Measured axial temperatures of premixed flames with different amounts of TTIP.

flame. Fig. 4 shows that the maximum flame temperature in the axial direction increases with increasing the TTIP concentration from $0.22 \%$ to $0.6 \%$. This was mainly attributed to the oxidation of TTIP. Although the presence of synthesized particles tends to increase the radiative loss from the flame and thus lower the flame temperature, this effect appears to be insignificant for the TTIP concentrations adopted in this study. Gas temperatures at the burner exit varied between 400 and $500 \mathrm{~K}$ in Fig. 4 were caused by the fact that premixed mixtures containing TTIP were preheated at $125{ }^{\circ} \mathrm{C}(398 \mathrm{~K})$ to prevent TTIP vapor from condensation, and by the heat feedback from the postflame region.

\subsection{Effect of flame condition on phase composition of product particles}

Fig. 5 shows a set of XRD spectra of collected product particles (at $h=7.5 \mathrm{~cm}$ ), which were synthesized in $\mathrm{CH}_{4} / \mathrm{O}_{2} /$

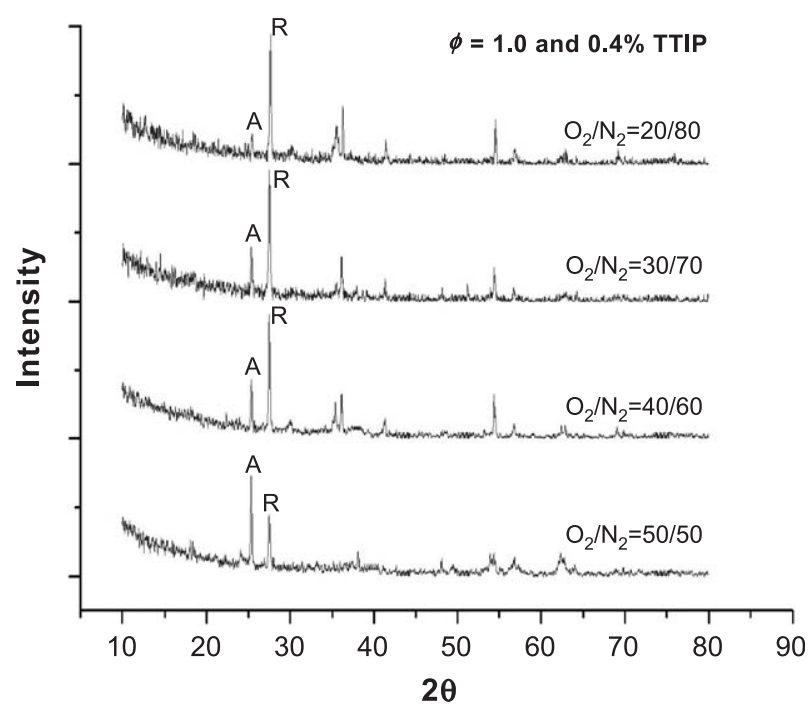

Fig. 5. XRD spectra of product particles synthesized in premixed flames with different $\mathrm{O}_{2}$ to $\mathrm{N}_{2}$ molar ratios in oxidizer. 
$\mathrm{N}_{2}$ premixed flames with the same equivalence ratio $(\phi)$ of 1.0 and TTIP concentration of $0.4 \%$, but with different molar ratios of oxygen to nitrogen $\left(\mathrm{O}_{2} / \mathrm{N}_{2}\right)$ in the oxidizer. The XRD spectrum indicates that as-synthesized powders consist of both anatase and rutile titania. As shown in Fig. 5, the intensity of the strongest peak for the anatase titania (labeled $\mathrm{A}$ at $2 \theta=25.3^{\circ}$ ) increases with an increase in the $\mathrm{O}_{2}$ to $\mathrm{N}_{2}$ molar ratio, implying that the anatase content in the product powder increases with the $\mathrm{O}_{2}$ concentration in the mixture. In contrast, the intensity of the strongest peak for the rutile phase (labeled $\mathrm{R}$ at $2 \theta=27.5^{\circ}$ ) is decreased by increasing the $\mathrm{O}_{2}$ to $\mathrm{N}_{2}$ molar ratio. In agreement with Pratsinis et al. [6] and Rulison et al. [7], this result suggests the higher oxygen concentration in the reactant mixture the higher anatase content in the product powder, because of the relatively high oxygen availability during the $\mathrm{TiO}_{2}$ particle formation. It is important to note that although the increase of oxygen mole fraction in the oxidizer led to an increase in flame temperature, the increasing anatase content shown in Fig. 5 was not attributed to the increase of flame temperature. The effect of flame temperature on the crystalline phase of titania is presented in Fig. 6.

Based upon the quantitative analysis presented by Spurr and Myers [21], the variation of anatase weight fraction (wt.\%) in the collected $\mathrm{TiO}_{2}$ particles (at $h=7.5 \mathrm{~cm}$ ) with the $\mathrm{O}_{2}$ mole fraction in the oxidizer is shown in Fig. 6. Results show a significant increase in anatase content with the $\mathrm{O}_{2}$ concentration in the oxidizer. For example, in a flame with $\phi=0.7$ and TTIP concentration of $0.4 \%$, the anatase content of about 23 wt. $\%$ at $\mathrm{O}_{2} / \mathrm{N}_{2}=20 / 80$ in the oxidizer stream increases up to 90 wt. $\%$ at $\mathrm{O}_{2} / \mathrm{N}_{2}=50 / 50$. This pronounced influence of oxidant composition on the crystalline phase of titania was also observed by Zhu and Pratsinis [22] in a diffusion flame reactor. Results by Zhu and Pratsinis [22] showed that when pure oxygen was used as the oxidizer the flame yielded spherical anatase particles, while using air as the oxidant resulted in aggregated particles with significant fraction of rutile. As indicated by

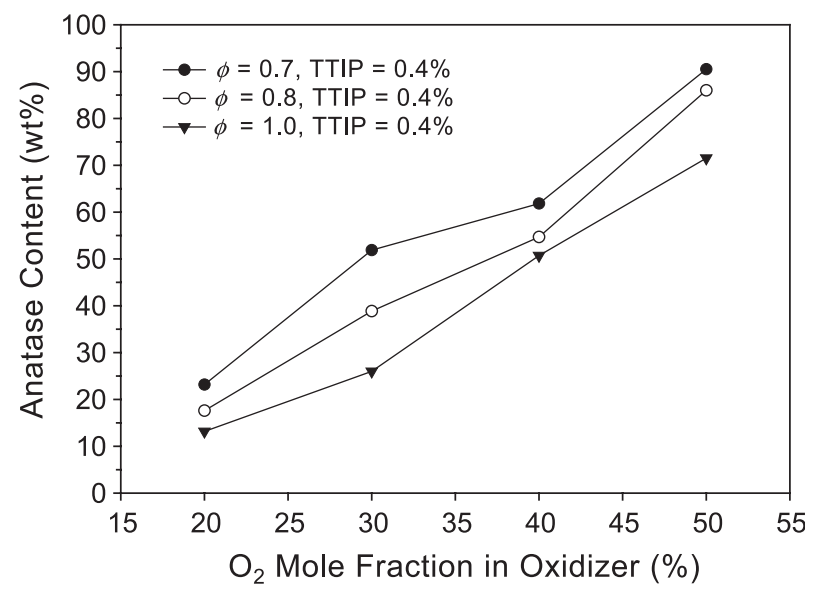

Fig. 6. Effect of $\mathrm{O}_{2}$ mole fraction in oxidizer on anatase content of $\mathrm{TiO}_{2}$ particles.

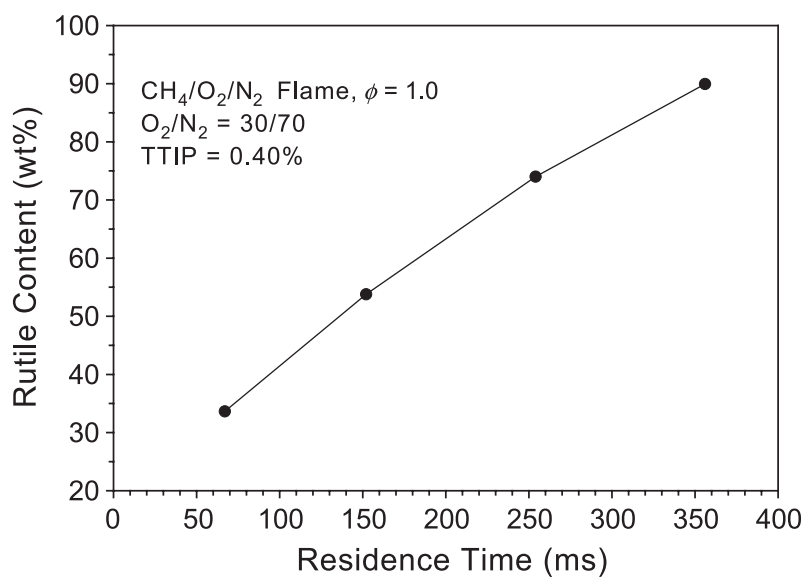

Fig. 7. Effect of residence time of particles in flame on rutile content of $\mathrm{TiO}_{2}$ particles.

Rulison et al. [7], the transformation of anatase to rutile $\mathrm{TiO}_{2}$ phase is promoted by the high concentration of oxygen vacancies, which increase with decreasing ambient oxygen concentration. Therefore, the lack of rutile $\mathrm{TiO}_{2}$ in product powders yielded in the flame with high $\mathrm{O}_{2}$ to $\mathrm{N}_{2}$ ratios in the oxidant is mainly due to the high oxygen concentration, which leads to a low concentration of oxygen vacancies.

Fig. 6 also reveals that at a constant $\mathrm{O}_{2}$ to $\mathrm{N}_{2}$ ratio anatase weight fraction deceases with increasing flame equivalence ratio, which causes an increase in flame temperature. This result confirms the increase of the rate of transformation from anatase to rutile phase with temperature, since the formation of rutile phase from anatase requires substantial atomic rearrangement that is facilitated by high temperatures [7]. This observation might also be caused by the particle residence time at high temperatures. Temperature profiles shown in Fig. 2 suggest that the particle should experience a relatively longer residence time at high temperatures in the flame of $\phi=1.0$ than in those of $\phi=0.8$ and 0.7 .

The effect of particle residence time in flame on the phase composition of titania particles was further studied by collecting the product at different heights $(h)$ above the burner exit. Fig. 7 presents the rutile content in the product collected at $h=2.0,4.5,7.5$, and $10.5 \mathrm{~cm}$, which correspond to the particle residence times being 67, 152, 254 and 356 ms, respectively. As shown in Fig. 7, an obvious increase in the rutile content of the product powder with the residence time was observed. This result is consistent with the observation by Vemury and Pratsinis [13], indicating that the reduction of particle residence time results in a lower level of crystallinity.

The effect of TTIP concentration on the phase composition of product particles (collected at $h=7.5 \mathrm{~cm}$ ) is shown in Figs. 8 and 9 for premixed flames with $\phi=0.8$ and 1.0, respectively. The anatase content was found to decrease with the increase of the TTIP concentration. This finding is attributed to the change in the flame temperature, which 


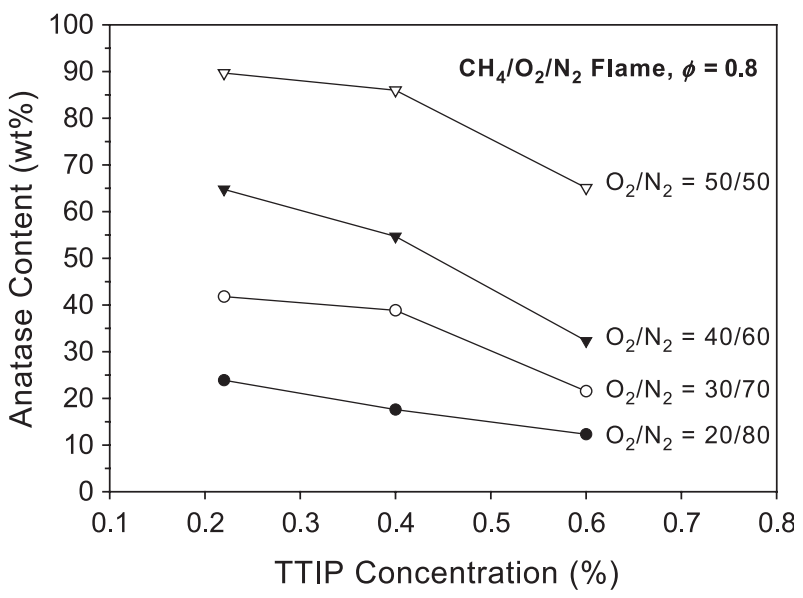

Fig. 8. Effect of TTIP concentration on anatase content of $\mathrm{TiO}_{2}$ particles synthesized in premixed flame with $\phi=0.8$.

increases with increasing TTIP concentration. Since the transformation of anatase to rutile is enhanced by higher flame temperature, the anatase content is increased in the flame added with a larger amount of TTIP. As also can be seen in Figs. 8 and 9, the anatase fraction increases considerably with the increase of $\mathrm{O}_{2}$ to $\mathrm{N}_{2}$ ratio, because of the substantial influence of oxidizer composition on the titania phase discussed in Fig. 6.

\subsection{Effect of HMDS dopant on phase composition of product particles}

Fig. 10 shows a set of XRD spectra of product powders synthesized under a $0.4 \%$ TTIP-added $\mathrm{CH}_{4} / \mathrm{O}_{2} / \mathrm{N}_{2}$ premixed flame doped with different amounts of HMDS. As shown in Fig. 10, at $\mathrm{Si}$ to $\mathrm{Ti}$ atomic ratios $(\mathrm{Si} / \mathrm{Ti})$ equal to 0.205 and 0.3 , the strongest peaks of both anatase and rutile titania are clearly observable in the spectra. However, when the HMDS doping concentrations was increased up to $\mathrm{Si} / \mathrm{Ti}=0.375$ and 0.45 , the characteristic peaks of $\mathrm{TiO}_{2}$ were no longer

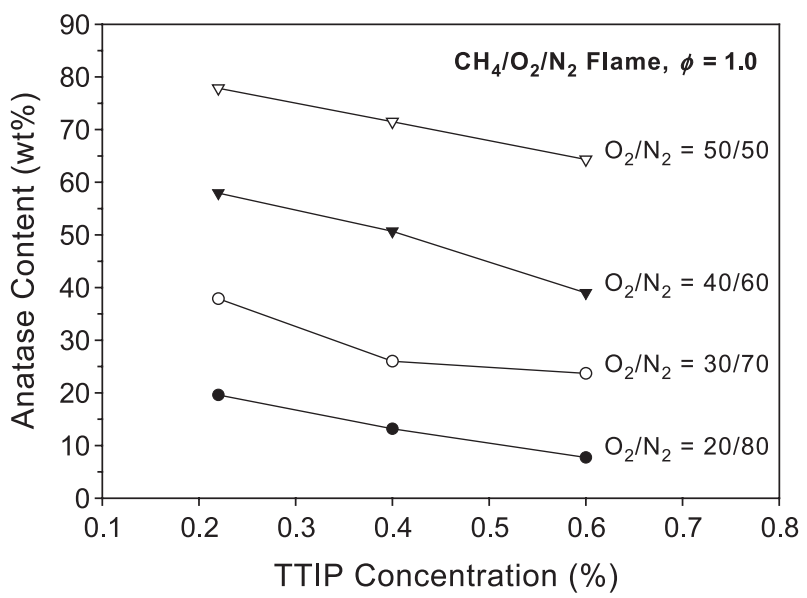

Fig. 9. Effect of TTIP concentration on anatase content of $\mathrm{TiO}_{2}$ particles synthesized in premixed flame with $\phi=1.0$.

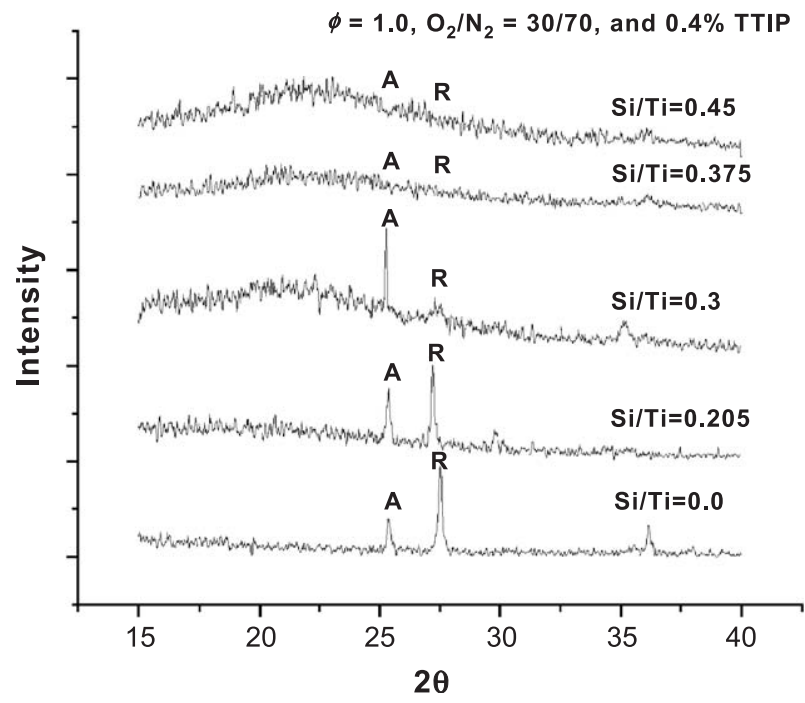

Fig. 10. XRD spectra of product particles synthesized in premixed flames doped with different amounts of HMDS.

detectable and the XRD spectra exhibited amorphous patterns. This implies without formation of any crystalline phases when the doping concentration of HMDS was above 0.375. According to Hung and Katz [11], at low Si to Ti ratios the synthesized $\mathrm{TiO}_{2}$ particles were attached with discrete $\mathrm{SiO}_{2}$ particles, which were produced from the oxidation of Si dopant. At high Si to Ti ratios, however, a layer of $\mathrm{SiO}_{2}$ was formed on the surface of $\mathrm{TiO}_{2}$ particles [11]. It is useful to note that the formation of $\mathrm{SiO}_{2}$ particles in premixed flames using HMDS as the Si precursor was experimentally confirmed by Yeh et al. [20]. Thus, the amorphous XRD patterns shown in Fig. 10 could be attributed to the formation of amorphous silica $\left(\mathrm{SiO}_{2}\right)$ particles.

Compared with the $\mathrm{TiO}_{2}$ particles formed without doping HMDS, Fig. 10 also indicates that the intensity of the

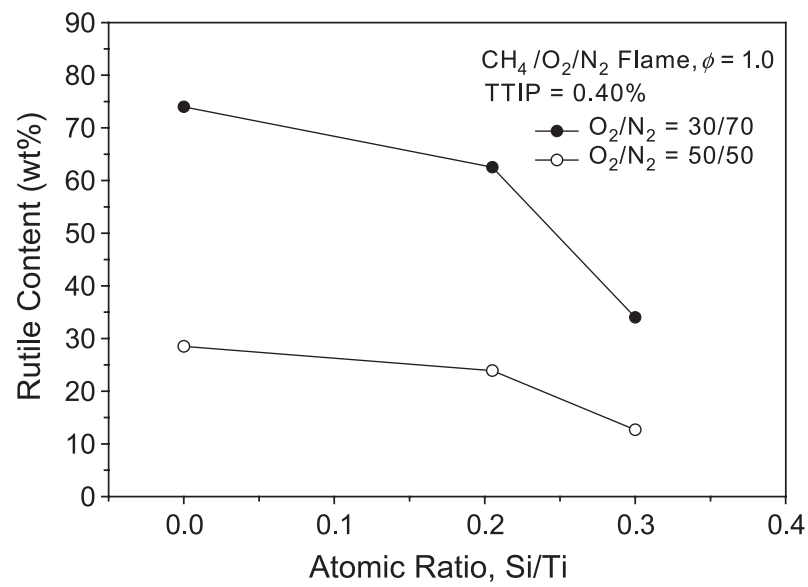

Fig. 11. Effect of HMDS concentration on rutile content of $\mathrm{TiO}_{2}$ particles synthesized in premixed flames with different $\mathrm{O}_{2}$ to $\mathrm{N}_{2}$ molar ratios in oxidizer. 
strongest peak for anatase titania increases with the $\mathrm{Si}$ to $\mathrm{Ti}$ atomic ratio. On the other hand, the intensity of XRD peak signifies the rutile titania decreases with the HMDS concentration. This implies that the doping of HMDS appears to favor the formation of anatase titania. The effect of $\mathrm{Si}$ dopant concentration on the rutile weight fraction of $\mathrm{TiO}_{2}$ particles is shown in Fig. 11. In agreement with Vemury and

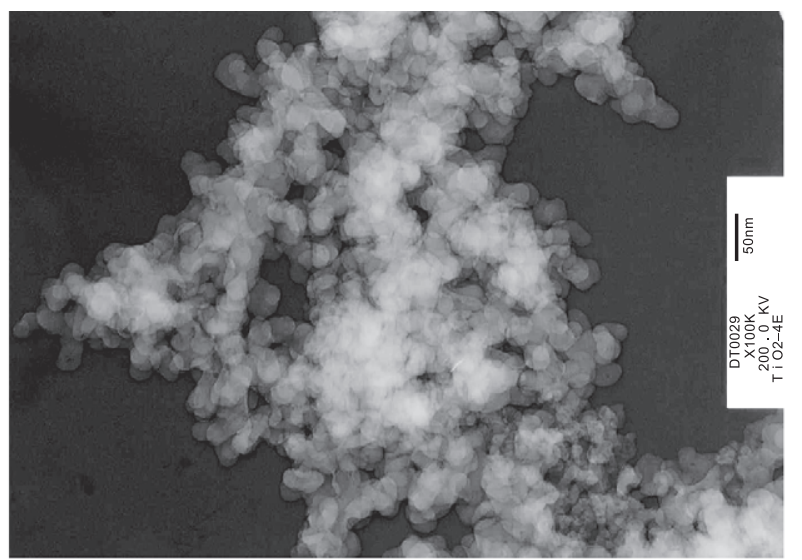

(a) $h=2.0 \mathrm{~cm}$

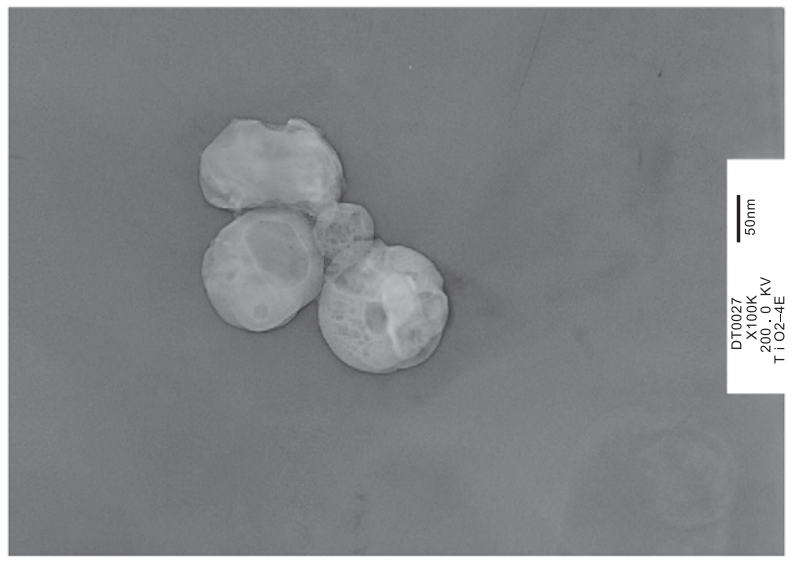

(b) $h=4.5 \mathrm{~cm}$

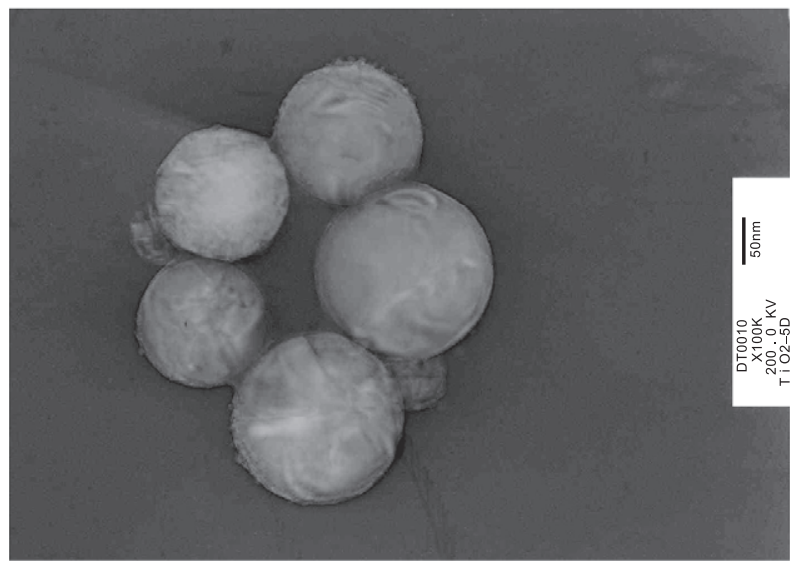

(c) $h=7.5 \mathrm{~cm}$

Fig. 12. TEM micrographs of synthesized $\mathrm{TiO}_{2}$ particles (in flame with $\phi=1.0, \mathrm{O}_{2} / \mathrm{N}_{2}=50 / 50$, and $0.4 \%$ TTIP) collected at different axial heights above burner exit: (a) $h=2.0 \mathrm{~cm}$, (b) $h=4.5 \mathrm{~cm}$, and (c) $h=7.5 \mathrm{~cm}$.

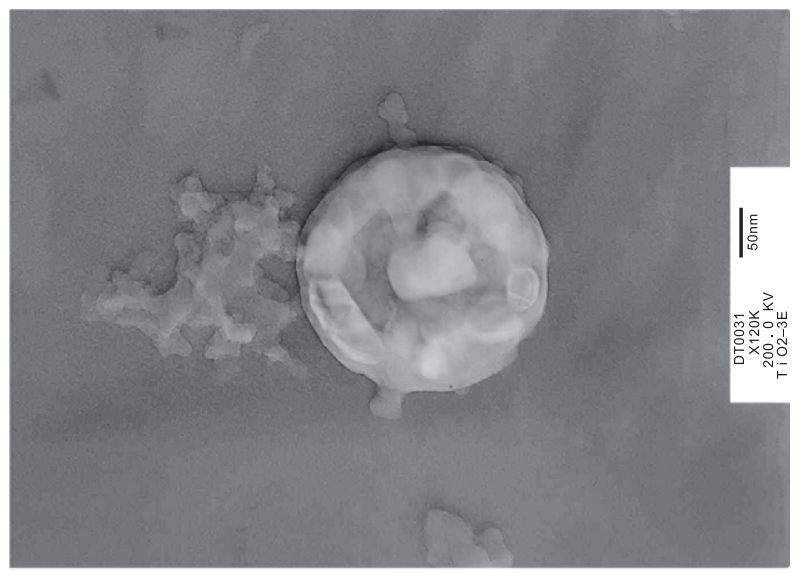

(a) $\mathrm{Si} / \mathrm{Ti}=0.205$

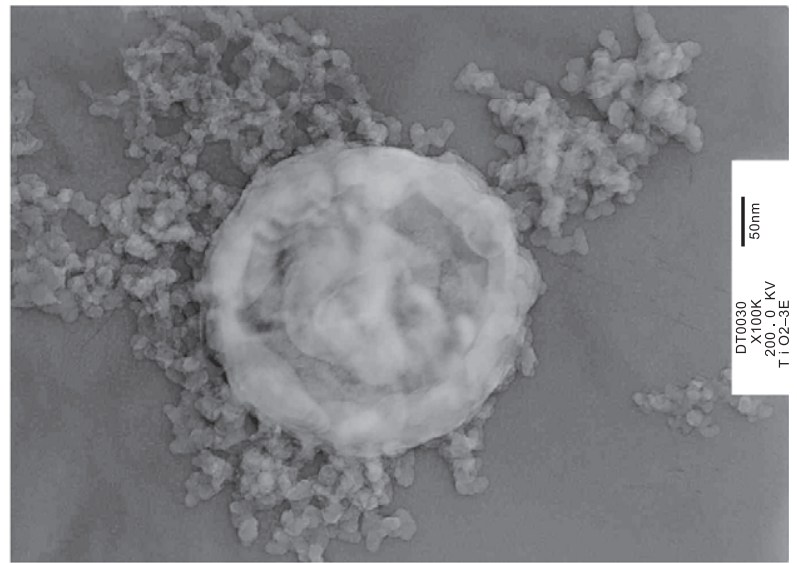

(b) $\mathrm{Si} / \mathrm{Ti}=0.30$

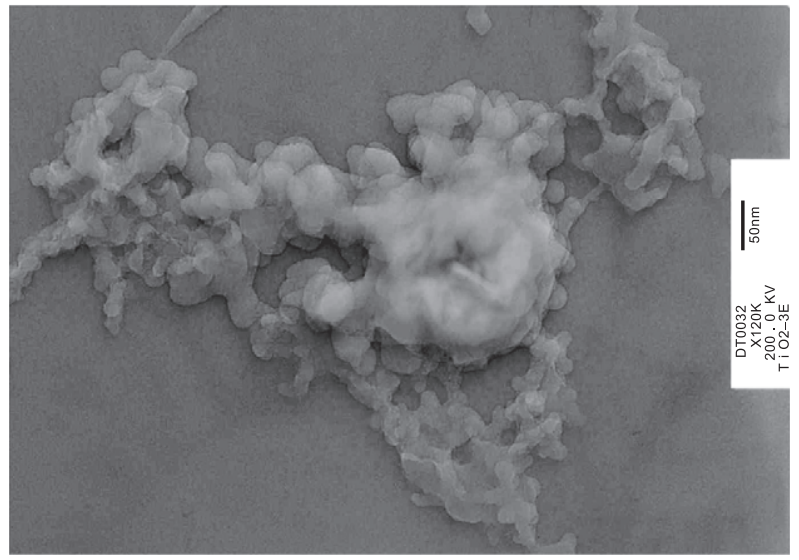

(c) $\mathrm{Si} / \mathrm{Ti}=0.375$

Fig. 13. TEM micrographs of product particles synthesized in premixed flames $\left(\phi=1.0, \mathrm{O}_{2} / \mathrm{N}_{2}=50 / 50\right.$, and $0.4 \%$ TTIP) doped with different amounts of HMDS: (a) $\mathrm{Si} / \mathrm{Ti}=0.205$, (b) $\mathrm{Si} / \mathrm{Ti}=0.30$, and (c) $\mathrm{Si} / \mathrm{Ti}=0.375$.

Pratsinis [8], the rutile content in the synthesized $\mathrm{TiO}_{2}$ decreases with increasing the $\mathrm{Si}$ to $\mathrm{Ti}$ atomic ratio. As shown in Fig. 11, the rutile content of about 74 wt.\% for the undoped flame with $\mathrm{O}_{2} / \mathrm{N}_{2}=30 / 70$ decreases to about 35 wt. $\%$ at $\mathrm{Si} / \mathrm{Ti}=0.3$. Akhtar et al. [9] indicated that due to the ionic radius of $\mathrm{Si}^{4+}$ smaller than that of $\mathrm{Ti}^{4+}$, silicon cation is incorporated into the titania lattice interstitially, thus inhibiting the transformation of anatase to rutile. 


\subsection{Particle morphology}

Fig. 12(a)-(c) shows the TEM micrographs of $\mathrm{TiO}_{2}$ particles collected at different axial heights $(h)$ above the burner exit. At $h=2.0 \mathrm{~cm}$, small particles of about $20 \mathrm{~nm}$ were formed and agglomerated into large flocs. As these flocs flow upward into regions of higher temperature, they compact to form larger particles, as shown in Fig. 12(b). Subsequent surface growth and aggregation cause continued evolution of particles. Thus, nearly spherical $\mathrm{TiO}_{2}$ particles shown in Fig. 12(c) with diameters around 200$250 \mathrm{~nm}$ were formed at $h=7.5 \mathrm{~cm}$. These variations of particle morphology with increasing residence time and temperature nicely confirm the evolution of $\mathrm{TiO}_{2}$ particle formation sketched by Hung and Katz [11]. As far as the crystalline phase is concerned, the nanosize particles (around $20 \mathrm{~nm}$ ) collected at $h=2.0 \mathrm{~cm}$ should be made up of a significant fraction of anatase phase, since the rutile content will be increased by increasing residence time in flame.

Fig. 13(a)-(c) shows the TEM micrographs of collected product particles (at $h=7.5 \mathrm{~cm}$ ) under HMDS-doped flames with $\mathrm{Si} / \mathrm{Ti}=0.205,0.30$, and 0.375 , respectively. As shown in Fig. 13(a)-(c), the synthesized $\mathrm{SiO}_{2}$ particles are extensively aggregated and the primary particles are considerably smaller than the $\mathrm{TiO}_{2}$ particle. Moreover, at $\mathrm{Si} / \mathrm{Ti}=0.205$ only limited amount of $\mathrm{SiO}_{2}$ particles were made in flame. At $\mathrm{Si} / \mathrm{Ti}=0.30$, the agglomerates of synthesized $\mathrm{SiO}_{2}$ particles were obviously increased and some of them were attached on the $\mathrm{TiO}_{2}$ particle. When the HMDS concentration was increased up to $\mathrm{Si} / \mathrm{Ti}=0.375$, as shown in Fig. 13(c), the agglomerates of $\mathrm{SiO}_{2}$ particles became dominant in the product and almost no $\mathrm{TiO}_{2}$ particles was found. This observation is consistent with the amorphous XRD spectrum shown in Fig. 5 at $\mathrm{Si} / \mathrm{Ti}=0.375$. It is also useful to note that the $\mathrm{SiO}_{2}$ particles formed in premixed flames by the oxidation of HMDS [23] exhibit similar particle size and morphology to those shown in Fig. 13. This further verifies the formation of $\mathrm{SiO}_{2}$ nanoparticles when doping HMDS in titania synthesis flames.

\section{Conclusions}

The crystalline phase and particle morphology of titania synthesized by the oxidation of TTIP in premixed flames was affected by various experimental parameters considered in this study, such as flame temperature, oxygen concentration, particle residence time, precursor mole fraction, and dopant HMDS. Several important results obtained in this study were summarized below.

The change in oxidizer composition from $\mathrm{O}_{2} / \mathrm{N}_{2}=20 / 80$ to $50 / 50$ leads to a significant increase in anatase content of the product particles, due to the higher oxygen concentration during the particle formation. The rutile content of titania particles increases considerably with increasing the particle residence time at high temperatures. This implies that the transformation of anatase to rutile phase is greatly enhanced by the particle residence time. The variation of flame equivalence ratio from $\phi=0.7$ to 1.0 results in a decrease in anatase content, because of the higher flame temperature which favors the transformation of anatase to rutile phase. The decrease of anatase content was also found by increasing the TTIP concentration. This result was also attributed to the increase of flame temperature. The titania particles collected at $h=2 \mathrm{~cm}$ under undoped flames exhibit the agglomeration of small particles around $20 \mathrm{~nm}$. The growth of particles continued in the postflame region and nearly spherical particles of about $200-250 \mathrm{~nm}$ were formed at $h=7.5 \mathrm{~cm}$.

The dopant HMDS employed in this study plays a similar role to $\mathrm{SiCl}_{4}$, which inhibits the transformation of anatase to rutile phase. Therefore, the rutile content in the titania particles decreases with increasing the $\mathrm{Si}$ to $\mathrm{Ti}$ atomic ratio. Moreover, at $\mathrm{Si}$ to $\mathrm{Ti}$ atomic ratios less than 0.3 synthesized $\mathrm{TiO}_{2}$ particles were attached with the agglomerates of $\mathrm{SiO}_{2}$ particles. As the amount of HMDS was increased to reach the $\mathrm{Si}$ to $\mathrm{Ti}$ atomic ratio equal to 0.375 or higher, the agglomerates of $\mathrm{SiO}_{2}$ particles became dominant in the product and almost no formation of $\mathrm{TiO}_{2}$ crystals was observed.

\section{Acknowledgements}

This research was supported by the National Science Council of Republic of China under grant NSC 89-2212-E212-022.

\section{References}

[1] E.J. Mezey, Pigments and reinforcing agents, in: C.F. Powell, J.H. Oxley, J.M. Blocher Jr. (Eds.), Vapor Deposition, Wiley, New York, 1966, pp. 423-451.

[2] L. Znaidi, R. Séraphimova, J.F. Bocquet, C. Colbeau-Justin, C. Pommier, A semi-continuous process for the synthesis of nanosize $\mathrm{TiO}_{2}$ powders and their use as photocatalysts, Mater. Res. Bull. 36 (2001) 811-825.

[3] M.A. Fox, M.T. Dulay, Heterogeneous photocatalysis, Chem. Rev. 93 (1993) 341-357.

[4] S.E. Pratsinis, Flame aerosol synthesis of ceramic powders, Prog. Energy Combust. Sci. 24 (1998) 197-219.

[5] G.P. Fotou, S. Vemury, S.E. Pratsinis, Synthesis and evaluation of titania powders for photodestruction of phenol, Chem. Eng. Sci. 49 (24B) (1994) 4939-4948.

[6] S.E. Pratsinis, W. Zhu, S. Vemury, The role of gas mixing in flame synthesis of titania powders, Powder Technol. 86 (1996) 87-93.

[7] A.J. Rulison, P.F. Miquel, J.L. Katz, Titania and silica powders produced in a counterflow diffusion flame, J. Mater. Res. 11 (12) (1996) 3083-3089.

[8] S. Vemury, S.E. Pratsinis, Dopants in flame synthesis of titania, J. Am. Ceram. Soc. 78 (11) (1995) 2984-2992.

[9] M.K. Akhtar, S.E. Pratsinis, S.V.R. Mastrangelo, Dopants in vaporphase synthesis of titania powders, J. Am. Ceram. Soc. 75 (12) (1992) $3408-3416$. 
[10] M.K. Akhtar, S.E. Pratsinis, S.V.R. Mastrangelo, Vapor phase synthesis of Al-doped titania powders, J. Mater. Res. 9 (5) (1994) 1241-1249.

[11] C.H. Hung, J.L. Katz, Formation of mixed oxide powders in flames: Part I. $\mathrm{TiO}_{2}-\mathrm{SiO}_{2}$, J. Mater. Res. 7 (7) (1992) 1861-1869.

[12] C.H. Hung, P.F. Miquel, J.L. Katz, Formation of mixed oxide powders in flames: Part II. $\mathrm{SiO}_{2}-\mathrm{GeO}_{2}$ and $\mathrm{Al}_{2} \mathrm{O}_{3}-\mathrm{TiO}_{2}$, J. Mater. Res. 7 (7) (1992) $1870-1875$.

[13] S. Vemury, S.E. Pratsinis, Corona-assisted flame synthesis of ultrafine titania particles, Appl. Phys. Lett. 66 (24) (1995) 3275-3277.

[14] S. Vemury, S.E. Pratsinis, L. Kibbey, Electrically controlled flame synthesis of nanophase $\mathrm{TiO}_{2}, \mathrm{SiO}_{2}$, and $\mathrm{SnO}_{2}$ powders, J. Mater. Res. 12 (4) (1997) 1031-1042.

[15] D. Lee, M. Choi, Coalescence enhanced synthesis of nanoparticles to control size, morphology and crystalline phase at high concentrations, J. Aerosol. Sci. 33 (2002) 1-16.

[16] K.M.S. Khalil, M.I. Zaki, Synthesis of high surface area titania powders via basic hydrolysis of titanium(IV) isopropoxide, Powder Technol. 92 (1997) 233-239.

[17] O.I. Arabi-Katbi, S.E. Pratsinis, P.W. Morrison Jr., C.M. Megaridis, Monitoring the flame synthesis of $\mathrm{TiO}_{2}$ particles by in-situ FTIR spec- troscopy and thermophoretic sampling, Combust. Flame 124 (2001) $560-572$

[18] H.K. Kammler, S.E. Pratsinis, P.W. Morrison Jr., B. Hemmerling, Flame temperature measurements during electrically assisted aerosol synthesis of nanoparticles, Combust Flame 128 (2002) 369-381.

[19] K. Wegner, W.J. Stark, S.E. Pratsinis, Flame-nozzle synthesis of nanoparticles with closely controlled size, morphology, and crystallinity, Mater Lett 55 (2002) 318-321.

[20] C.L. Yeh, E. Zhao, H.K. Ma, An experimental investigation of combustion synthesis of silicon dioxide $\left(\mathrm{SiO}_{2}\right)$ particles in premixed flames, Combust. Sci. Technol. 173 (2001) 25-46.

[21] R.A. Spurr, H. Myers, Quantitative analysis of anatase-rutile mixtures with an X-ray diffractometer, Anal. Chem. 29 (1957) 760-762.

[22] W. Zhu, S.E. Pratsinis, Flame synthesis of nanosize particles: effect of flame configuration and oxidant composition, in: G.M. Chow, K.E. Gonsalves (Eds.), Nanotechnology, ACS Symp. Ser., vol. 622, 1996, pp. $64-78$.

[23] C.L. Yeh, E. Zhao, H.K. Ma, Gas-phase combustion synthesis of $\mathrm{SiO}_{2}$ nanoparticles from hexamethyldisiloxane, Trans. Aeronaut. Astronaut. Soc. Rep. China 35 (2003) 249-255. 